\title{
Clinical and radiological features of osteonecrosis in systemic lupus erythematosus*
}

\author{
I. D. GRIFFITHS, R. N. MAINI, AND J. T. SCOTT \\ From the Kennedy Institute of Rheumatology, London
}

SUMMARY Symptomatic osteonecrosis occurred in 8 out of 68 patients with systemic lupus erythematosus. Multiple joints were involved in 3 patients, and weight-bearing joints were most frequently affected. Osteonecrosis tended to occur early in the disease, and the patients had all received corticosteroids. Symptoms tended to occur when the disease had progressed from an active phase into one of clinical and serological quiescence. In weight-bearing joints classical radiological changes were often absent at the onset of symptoms.

The survival rates of patients with systemic lupus erythematosus (SLE) have improved considerably in the past 20 years (Dubois, 1976) and this is mainly due to better therapy and the recognition of milder forms of the disease. However, with the increased life expectancy of SLE patients complications which may produce marked functional impairment, such as avascular necrosis or osteonecrosis, become increasingly important in the long-term management of these patients. In this paper we have preferred to use the term osteonecrosis instead of avascular necrosis of bone because we feel that the latter term implies a pathogenetic mechanism which has not yet been clearly demonstrated in SLE (Jones, 1978).

Osteonecrosis was first described in SLE patients by Dubois and Cozens (1960), and subsequent reviews have reported incidences varying from $5 \%$ to $40 \%$ (Bergstein et al., 1974; Dubois, 1976). We have retrospectively reviewed the incidence, clinical features, therapy, and serological abnormalities in patients who have developed symptomatic osteonecrosis in the SLE population we have followed.

\section{Patients and methods}

Patients were reviewed who had had SLE for at least 2 years since the onset of first symptoms and who had been followed up in the clinic for at least 1 year. All patients had a minimum of 3 of the

Accepted for publication 10 October 1978.

*Presented at a meeting of the Heberden Society in London 2nd March 1978.

Correspondence to Dr I. D. Griffiths, Department of Rheumatology, Freeman Hospital, Newcastle upon Tyne.
American Rheumatism Association (ARA) criteria for SLE (excluding LE cells) (Cohen et al., 1971) and either positive LE cells or antinuclear antibodies. All patients had standard $x$-rays of the hands, feet, and chest, and no patient had radiological evidence of joint erosion. Other joint radiographs were taken only if symptoms indicated. A total of 68 patients were reviewed.

The diagnosis of osteonecrosis was in all cases based on both the clinical picture of continuing joint pain in the absence of persistent synovitis and typical radiological changes. The radiological features which we considered to be indicative of osteonecrosis were based on the British Medical Research Council's recommendations (McCullum and Walder, 1966). All our patients had the juxtaarticular type of lesion rather than the shaft lesions. The appearances varied from either localised lytic or increased density lesions within an intact articular cortex to structural failure of the articular cortex with subchondral fractures, or collapse of articular cartilage or reabsorption of bone. Many patients showed a progression of radiological changes.

\section{Results}

Eight out of the 68 patients developed symptomatic osteonecrosis. A total of 13 joints were involved, 3 of the patients having multiple joint involvement. The clinical features of the patients with and without osteonecrosis are compared in Table 1. No statistical difference in the incidence of any feature was observed between the 2 groups, but renal involvement was more common in the osteo- 
Table 1 Clinical features of SLE patients with osteonecrosis compared to those without

\begin{tabular}{lll}
\hline & $\begin{array}{l}\text { Patients } \text { with } \\
\text { osteonecrosis }\end{array}$ & $\begin{array}{l}\text { Patients without } \\
\text { osteonecrosis }\end{array}$ \\
\hline Total number & 8 & 60 \\
Facial rash & $3(28 \%)$ & $29(47 \%)$ \\
Discoid lupus & 0 & $3(5 \%)$ \\
Raynaud's phenomenon & $4(50 \%)$ & $31(58 \%)$ \\
Alopecia & $4(50 \%)$ & $23(39 \%)$ \\
Photosensitivity & $1(13 \%)$ & $11(19 \%)$ \\
Oropharyngeal ulcers & $1(13 \%)$ & $12(22 \%)$ \\
Arthritis & $8(100 \%)$ & $55(92 \%)$ \\
Pleuropericardial disease & $3(38 \%)$ & $22(36 \%)$ \\
CNS involvement & $1(13 \%)$ & $15(25 \%)$ \\
LE cells & $7(88 \%)$ & $50(83 \%)$ \\
Proteinuria & $4(50 \%)$ & $17(29 \%)$ \\
Haematological features & $3(38 \%)$ & $24(39 \%)$ \\
\hline
\end{tabular}

necrosis group, and this may have had some bearing on therapy. Brief case histories of the patients with osteonecrosis are recorded below.

Case 1. A 52-year-old Canadian woman developed polyarthritis, pericarditis, alopecia, and oropharyngeal ulceration in December 1973. LE cells and ANA were positive. She was treated with prednisolone $100 \mathrm{mg}$ daily. The dose was rapidly reduced, but in June 1974 she had an episode of pleurisy, which responded to $40 \mathrm{mg}$ of prednisolone daily, gradually being reduced to $20 \mathrm{mg}$ daily by October 1974. At this stage the patient was well apart from some pain in the left hip. There was no history of preceding trauma. Initial radiographs were normal, but pain in the left hip persisted, and a repeat radiograph in May 1975 showed what we take to be osteonecrosis of the left acetabular margin (Fig. 1).
The disease had otherwise remained inactive and she? was receiving prednisolone $14 \mathrm{mg}$ daily.

Case 2. A 30-year-old Englishwoman developed polyarthritis, oropharyngeal ulceration, and leuco-등 penia in September 1970. ANA and LE cells weres positive. She was treated with prednisolone $40 \mathrm{mg}$ daily, gradually reducing to $10 \mathrm{mg}$ daily. In Decem ber 1971 she started to complain of pain in the left $t^{\text {s }}$ hip, and radiographs 1 month, 5 months, and $11 \vec{\circ}$ months later showed changes of progressive osteo- $-\overrightarrow{-}$ necrosis (Fig. 2). In May 1972 she complained of pain in the right hip, but $x$-rays of that joint werew normal; the pain resolved after 3 weeks' bed rest. The patient was maintained on prednisolone $10 \mathrm{mg}$ daily. In November 1972 she developed a nephrotic syndrome progressing to renal failure, from which $\vec{\omega}$ she died in February 1973.

Case 3. A 19-year-old Greek woman developed? polyarthritis and lymphadenopathy in May 1973.0 In December 1973 treatment with prednisolone was started. In April 1974 she was found to have्ठ proteinuria with granular casts in the urine, and $\mathrm{a}^{-}$ renal biopsy showed an active diffuse, proliferative glomerulonephritis. She also developed recurrento episodes of pleurisy and psychosis. ANA and LEO cells were positive, DNA binding $>2000$ units $/ \mathrm{ml}$ $\mathrm{C} 3, \mathrm{C} 4$, and $\mathrm{CH} 50$ values were all depressed $\overline{5}$ Haemoglobin electrophoresis was normal. She waš treated with prednisolone $60 \mathrm{mg}$ daily and azathio $\Omega$ prine $3 \mathrm{mg} / \mathrm{kg}$ body weight, and the disease became inactive by May 1974. The prednisolone was gradually reduced to $20 \mathrm{mg}$ daily, but she remained on
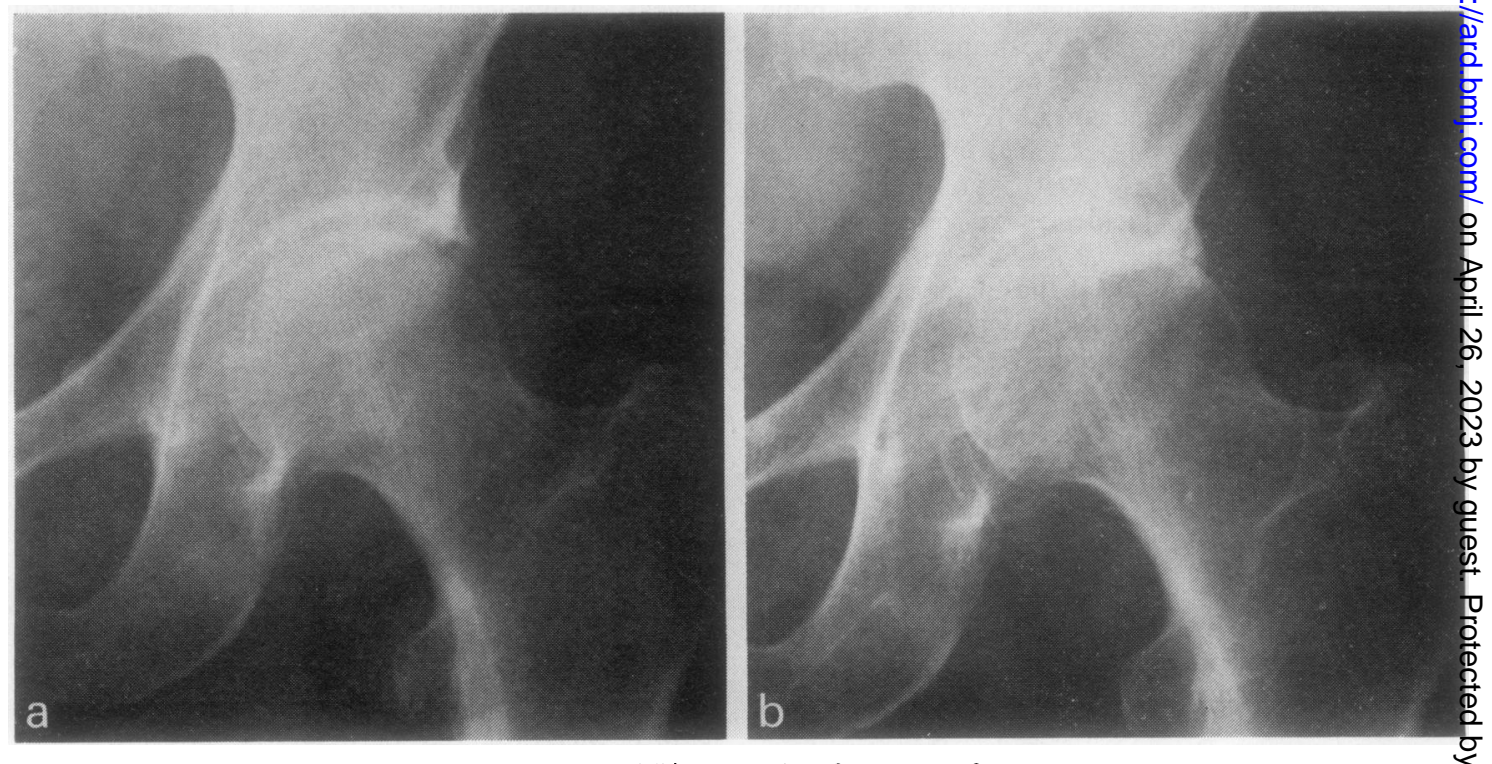

Fig. 1 Case 1. X-rays of left hip (a) 3 months and (b) 7 months after onset of symptoms 

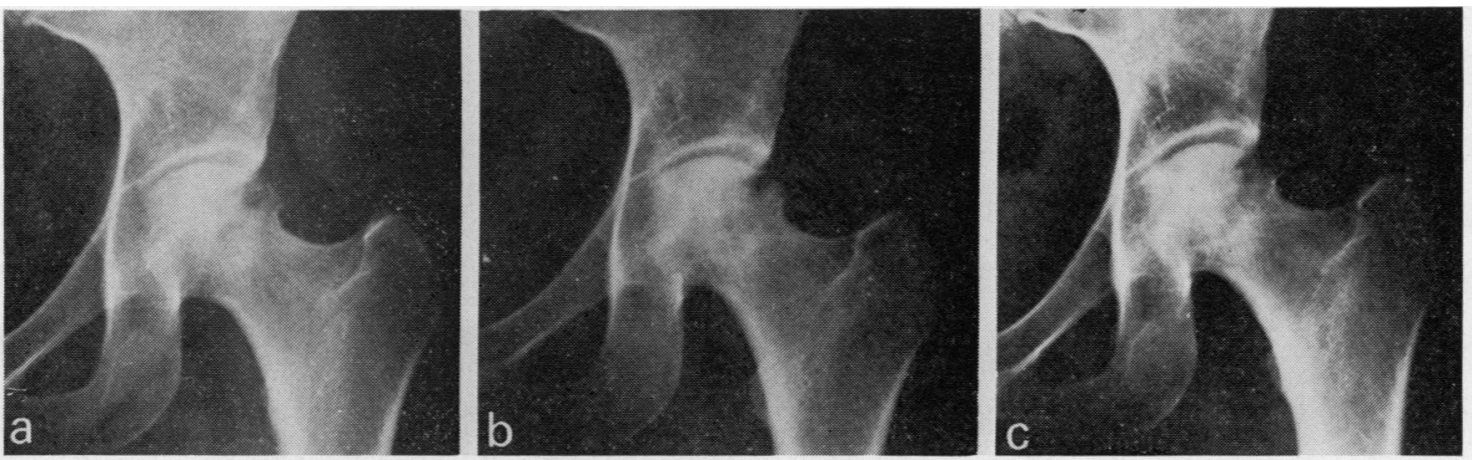

Fig. 2 Case 2. X-rays of left hip (a) 1 month, (b) 5 months, and (c) 11 months after onset of symptoms
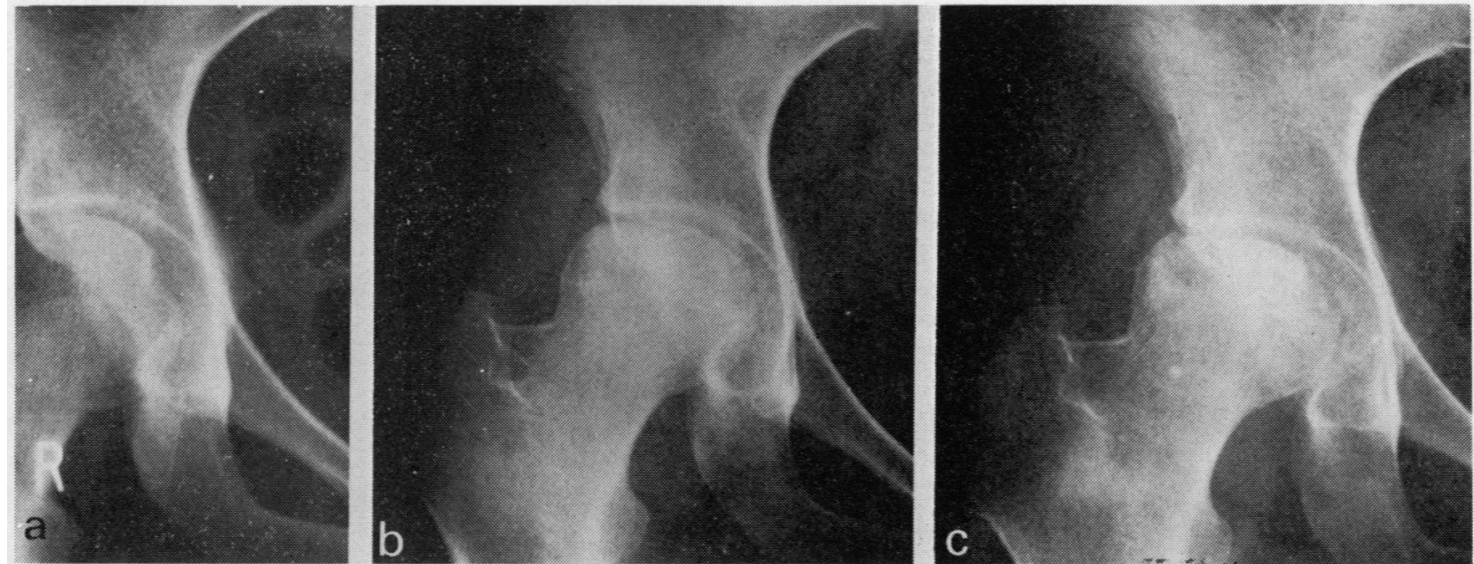

Fig. 3 Case 3. Control X-ray of (a) right hip (IVP) and appearances (b) 9 months and (c) 1 year after onset of symptoms
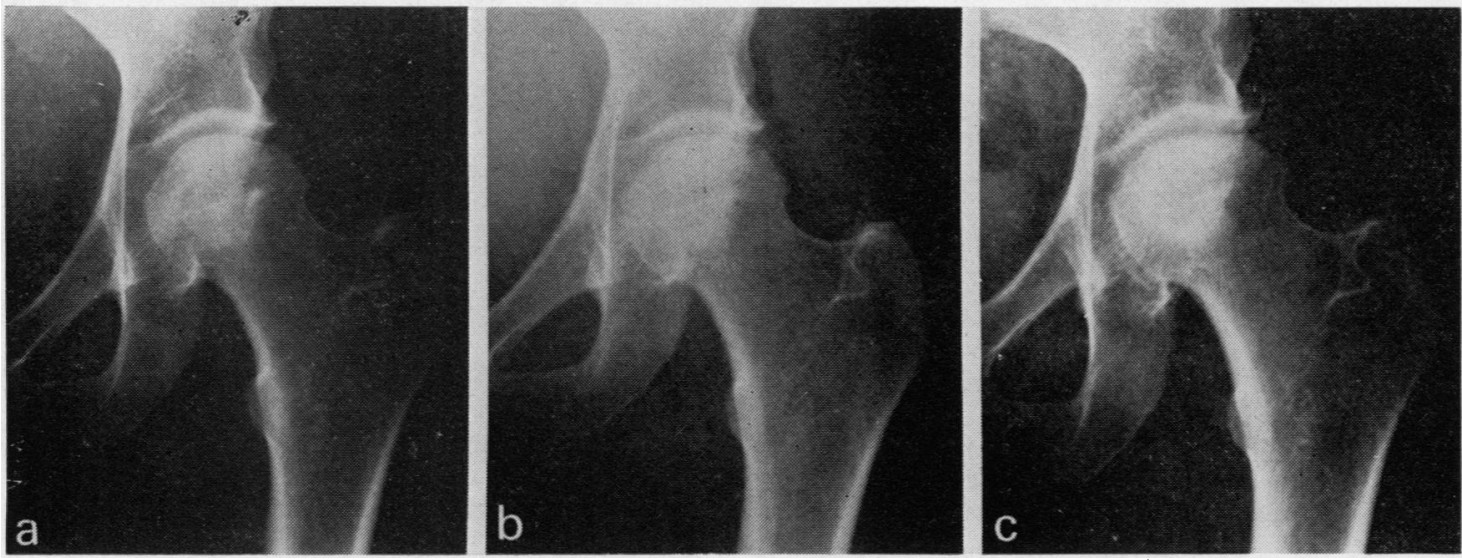

Fig. 4 Case 5. X-rays of left hip (a) 6 months, (b) 9 months, and (c) 22 months after onset of symptoms 
azathioprine. In May 1975, when the disease was quiescent both clinically and serologically, she started to complain of pain in the right hip, and radiographs in February 1976 revealed changes of osteonecrosis of the right femoral head, which progressed over the ensuing year in spite of prednisolone being reduced to $7 \mathrm{mg}$ daily (Fig. 3).

Case 4. A 28-year-old Egyptian woman developed polyarthritis, lymphadenopathy, facial rash, and frontal alopecia in 1974. LE cells and ANA were positive. Haemoglobin electrophoresis was normal. Treatment with prednisolone $20 \mathrm{mg}$ daily was started, and the dose was reduced to $10 \mathrm{mg}$ daily by early 1976. However, during 1976 the C3, C4, and CH50 values fell, and DNA antibodies rose to $>2000$ units $/ \mathrm{ml}$. She became acutely ill in September 1976, with joint pains and fever, and progressed into coma with a grossly abnormal EEG and brain scan. The prednisolone was increased to $100 \mathrm{mg}$ daily and cyclophosphamide given. The disease came into remission clinically and serologically by December 1976, and the prednisolone was reduced and the cyclophosphamide discontinued. She was discharged from hospital in December 1976 but shortly after discharge complained of pain in the right hip. An $x$-ray taken in June 1977 showed osteonecrosis of the right femoral head. At that time she was taking $19 \mathrm{mg}$ of prednisolone daily.

Case 5. A 25-year-old West Indian woman presented with a polyarthritis, Raynaud's phenomenon, and leucopenia in March 1973. DAT (differential

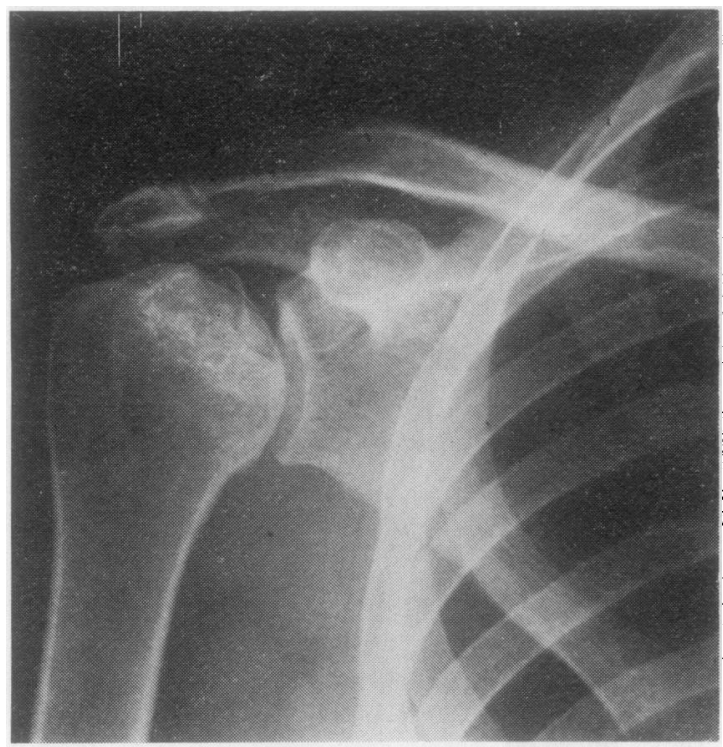

Fig. 5 Case 5. X-ray appearance of right shoulder at onset of symptoms in shoulder agglutination titre) and LE cells were negative but $t^{\frac{0}{9}}$ the ANA was positive. Haemoglobin electrophoresis was normal. In June 1973 she developed pleurisy and was treated with prednisolone $60 \mathrm{mg}$ daily then gradually reducing. She continued to have inter $-\overline{\bar{n}}$ mittent polyarthritis with synovitis, but the disease $\bar{D}$ became clinically inactive by November 1974. However, in April 1975, when she was takinges

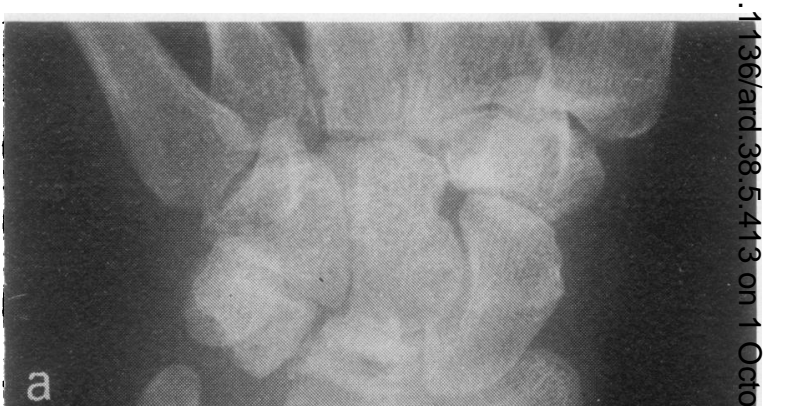

\section{a}

b

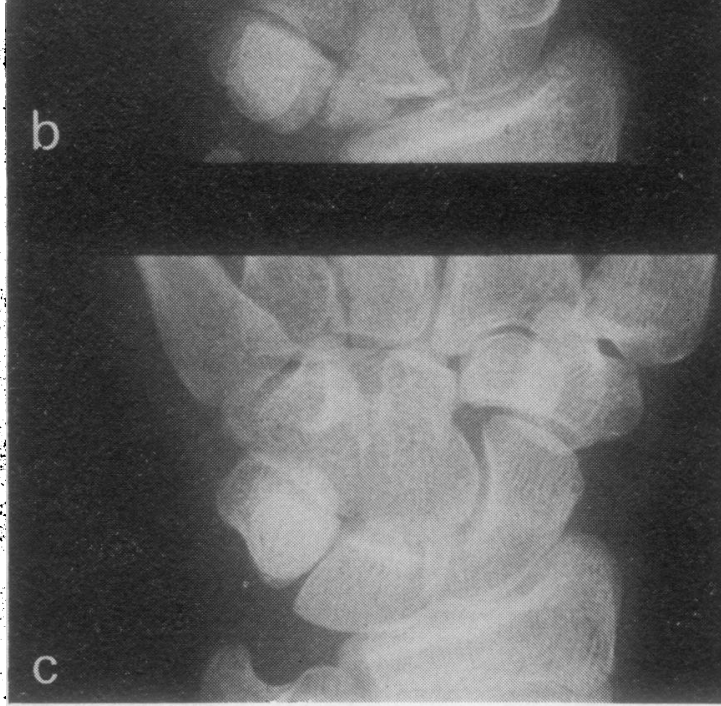

Fig. 6 Case 6. X-ray appearance of left carpus (a) 2 years before symptoms, (b) at onset of symptoms, and (c) 1 year later 
prednisolone $10 \mathrm{mg}$ daily, she complained of persistent pain in the left hip. Radiographs at that stage were normal but by October 1975 showed early changes and by January 1976 definite changes of osteonecrosis of the femoral head (Fig. 4). She was subsequently maintained on prednisolone $8 \mathrm{mg}$ daily and the disease remained well controlled and the patient ambulant. In February 1977 she developed pain in the right shoulder, with limited movement; radiographs showed changes of osteonecrosis of the right humeral head (Fig. 5).

Case 6. A 16-year-old English girl presented in April 1973 with polyarthritis, the left wrist being most severely affected, facial rash, photosensitivity, and Raynaud's phenomenon. LE cells and ANA were positive. Proteinuria was present, and renal biopsy showed an active, diffuse, proliferative glomerulone-

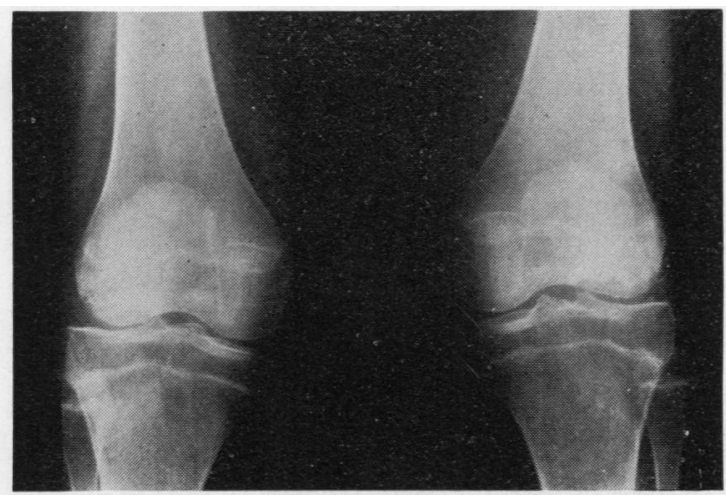

Fig. 7 Case 7. X-ray appearance of knees 1 year after onset of symptoms phritis. She was treated with prednisolone $40 \mathrm{mg}$ daily, which was gradually reduced, and the disease became generally quiescent apart from persisting proteinuria. In December 1973 azathioprine $3 \mathrm{mg} / \mathrm{kg}$ body weight was introduced. In June 1975 she started work as a nurse, but in September 1975, when taking $15 \mathrm{mg}$ prednisolone daily, she again complained of pain in the left wrist, with clinical evidence of synovitis. Radiographs then showed evidence of early osteonecrosis of the left lunate, which subsequently progressed (Fig. 6). The dose of prednisolone was gradually reduced to $10 \mathrm{mg}$ daily, and the patient continued in full-time nursing.

Case 7. A 14-year-old Pakistani girl presented in April 1973 with facial rash, arthralgia and proteinuria. LE cells and ANA were positive. Haemoglobin electrophoresis was normal. She was treated with prednisolone, and this was increased to $100 \mathrm{mg}$ daily in December 1973 because of the development of a nephrotic syndrome and worsening glomerular filtration rate (GFR). The disease gradually came into remission, but by June 1975 she started to complain of pain in both knees with swelling and synovitis. However, radiographs in June 1976 showed bilateral osteonecrosis of the lateral femoral condyles (Fig. 7). The disease was otherwise inactive apart from persisting proteinuria.

Case 8. A 46-year-old woman from Gibraltar presented with polyarthritis, psychosis, and pleurisy in 1964. LE cells and ANA were subsequently found to be positive, and she was treated with prednisolone $60 \mathrm{mg}$, reducing to $20 \mathrm{mg}$ daily, which she took until August 1974. At that stage she was grossly cushingoid, but the disease was otherwise inactive apart from peristent pain in the right shoulder. Radiographs

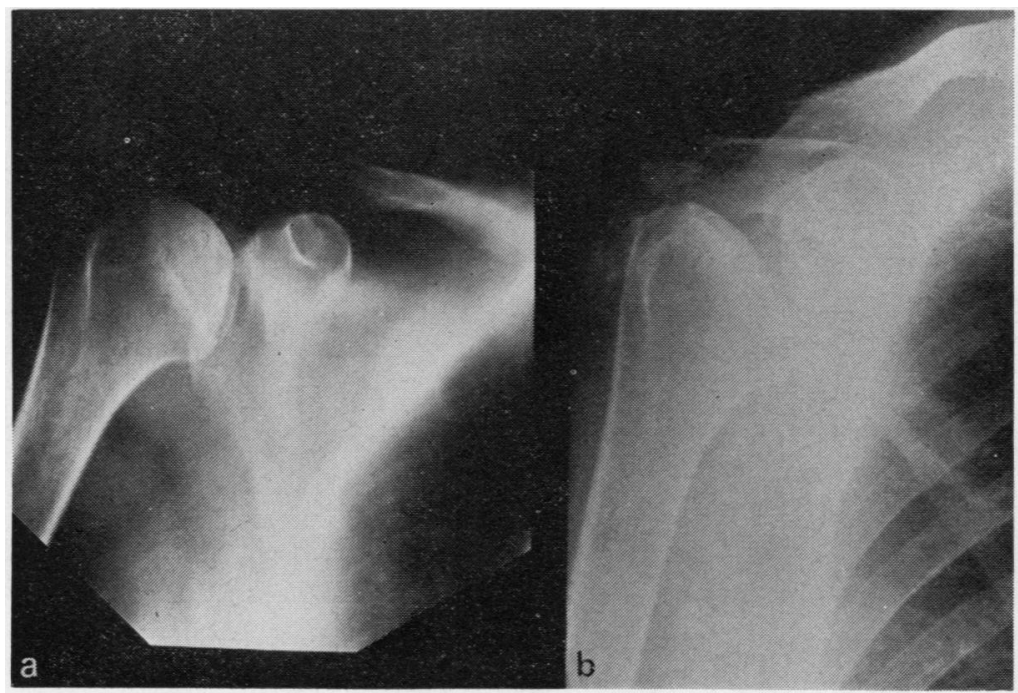

Fig. 8 Case 8. X-ray of right shoulder (a) at onset of symptoms and (b) 18 months later 
showed the presence of osteonecrosis of the head of the right humerus (Fig. 8). Azathioprine $3 \mathrm{mg} / \mathrm{kg}$ body weight was added but had to be discontinued after 1 month because of leucopenia. Prednisolone dosage was reduced to $10 \mathrm{mg}$ daily by June 1975 , and the disease remained clinically inactive. In July 1975 she fell and sustained a fracture of the surgical
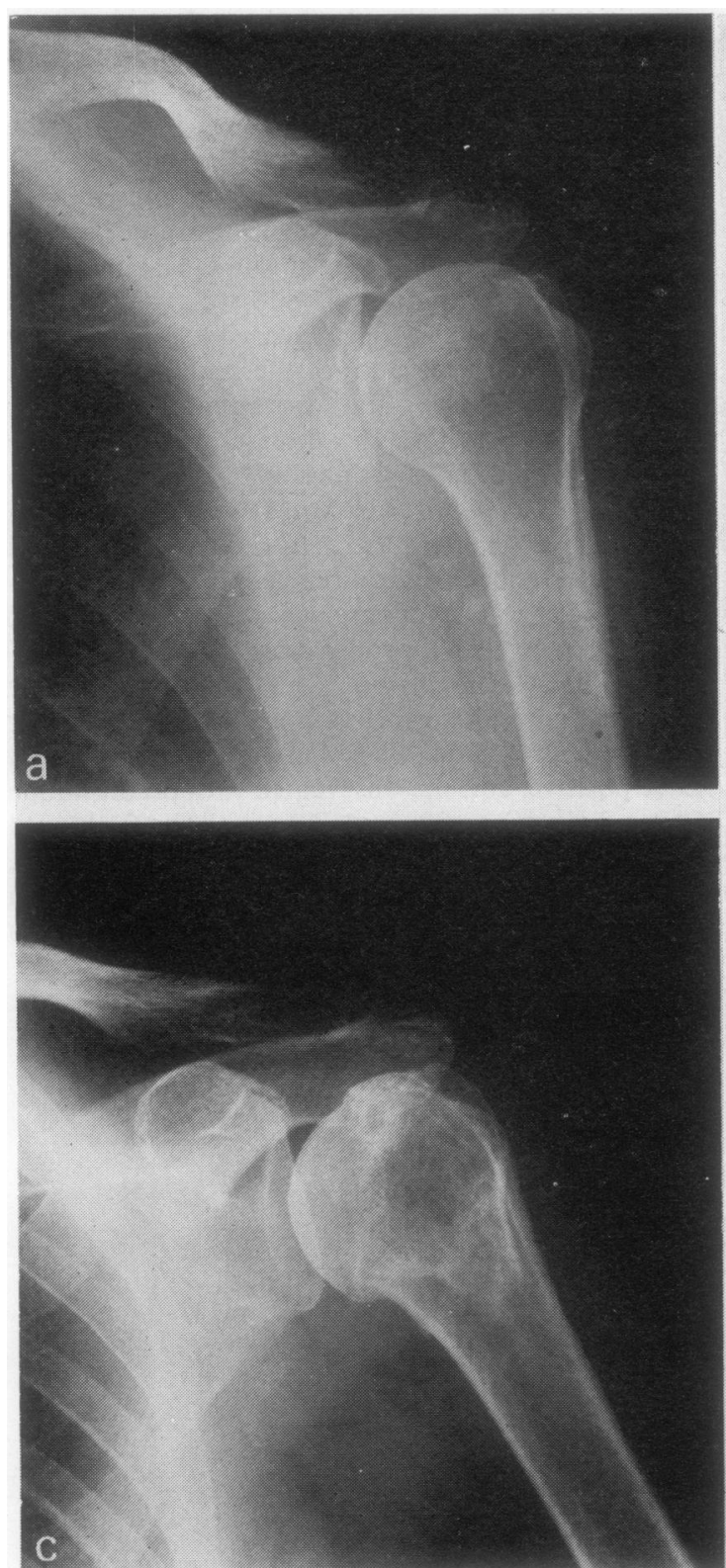

Fig. 9 Case 8. X-ray of left shoulder (a) before fracture, (b) 3 months, and (c) 5 months after fracture of left humerus, and (d) at onset of subsequent pain in shoulder 13 months after fracture neck of the left humerus, which had reunited without? residual symptoms by November 1975, but in August 1976 she complained of pain in the leff shoulder, with restricted movement, and $x$-raye evidence of osteonecrosis of the left humeral heac. was seen (Fig. 9). In February 1976 when taking prednisolone $6 \mathrm{mg}$ daily, she complained of pain in
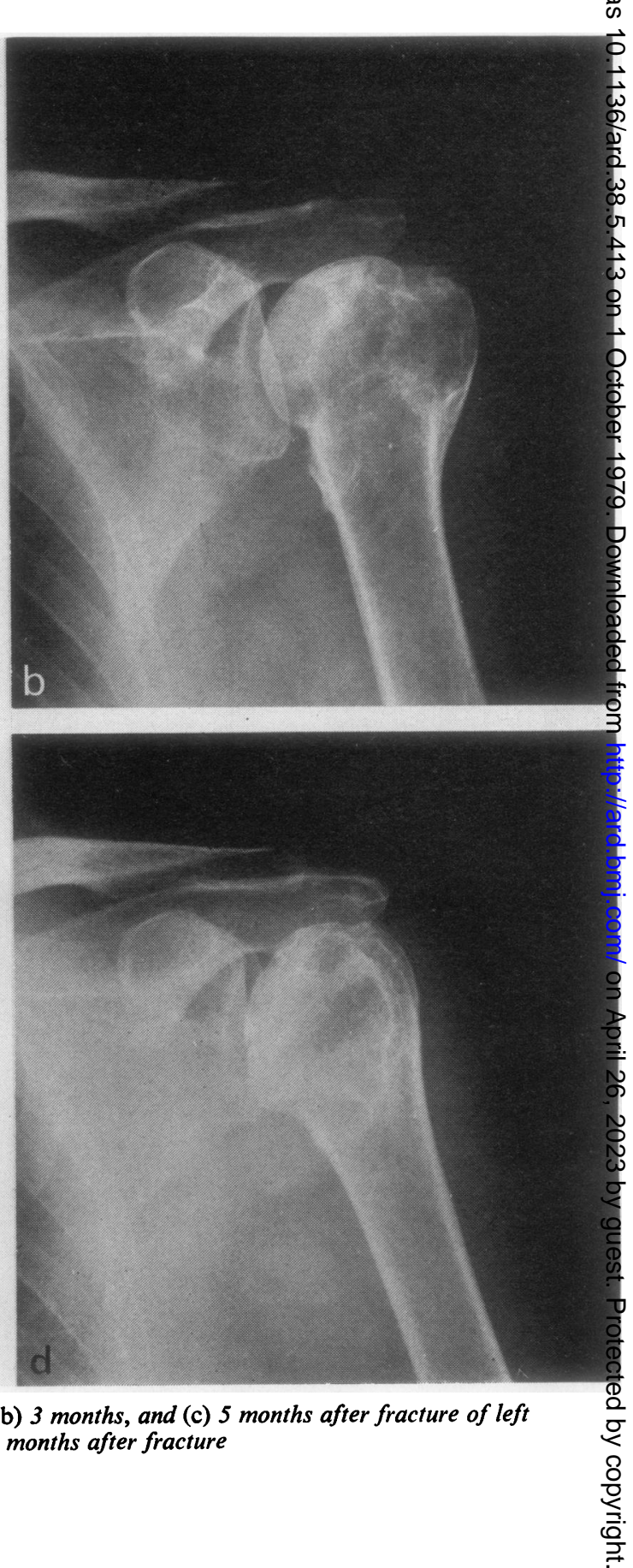
the left hip. Azathioprine $3 \mathrm{mg} / \mathrm{kg}$ body weight was reintroduced. Radiographs were normal at that stage but showed changes of osteonecrosis of the left femoral head by August 1976 (Fig. 10). The pain in the left hip became so troublesome that a total hip replacement was performed in February 1977, but the patient died suddenly of a pulmonary embolism on the 15th postoperative day.

When the maintenance dose of prednisolone prior to the onset of osteonecrosis was compared to the maintenance dose of prednisolone in patients without osteonecrosis statistically significant $(P<0.05)$
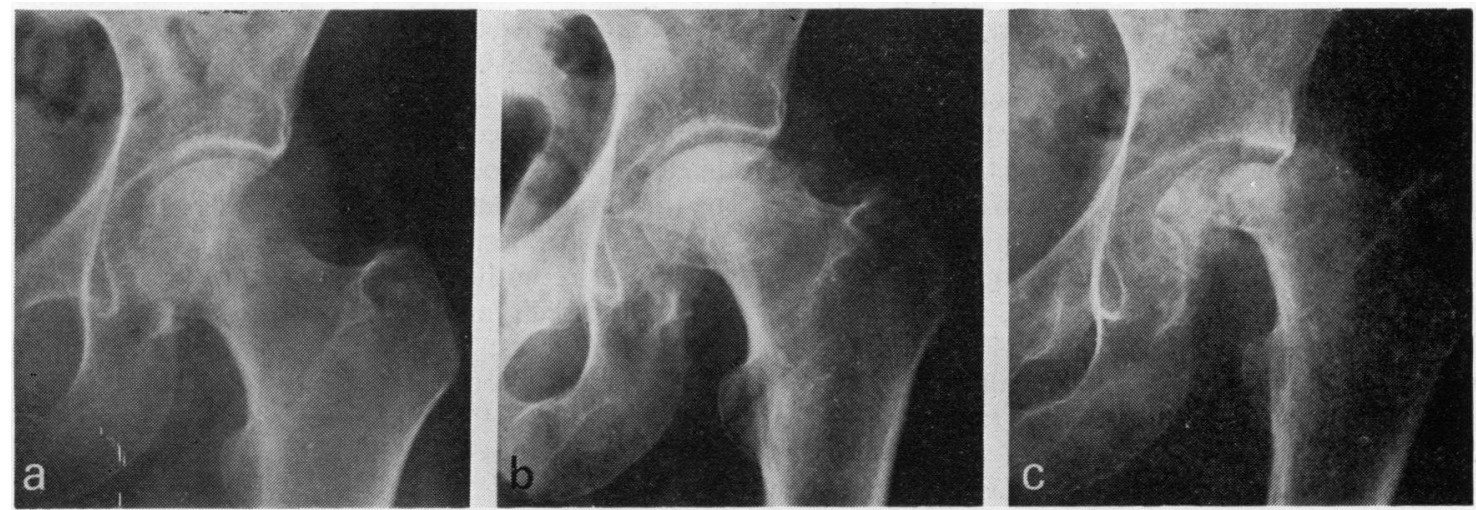

Fig. 10 Case 8. X-ray of left hip (a) 18 months before onset of pain and appearances, (b) 6 months, and (c) 12 months after onset of symptoms
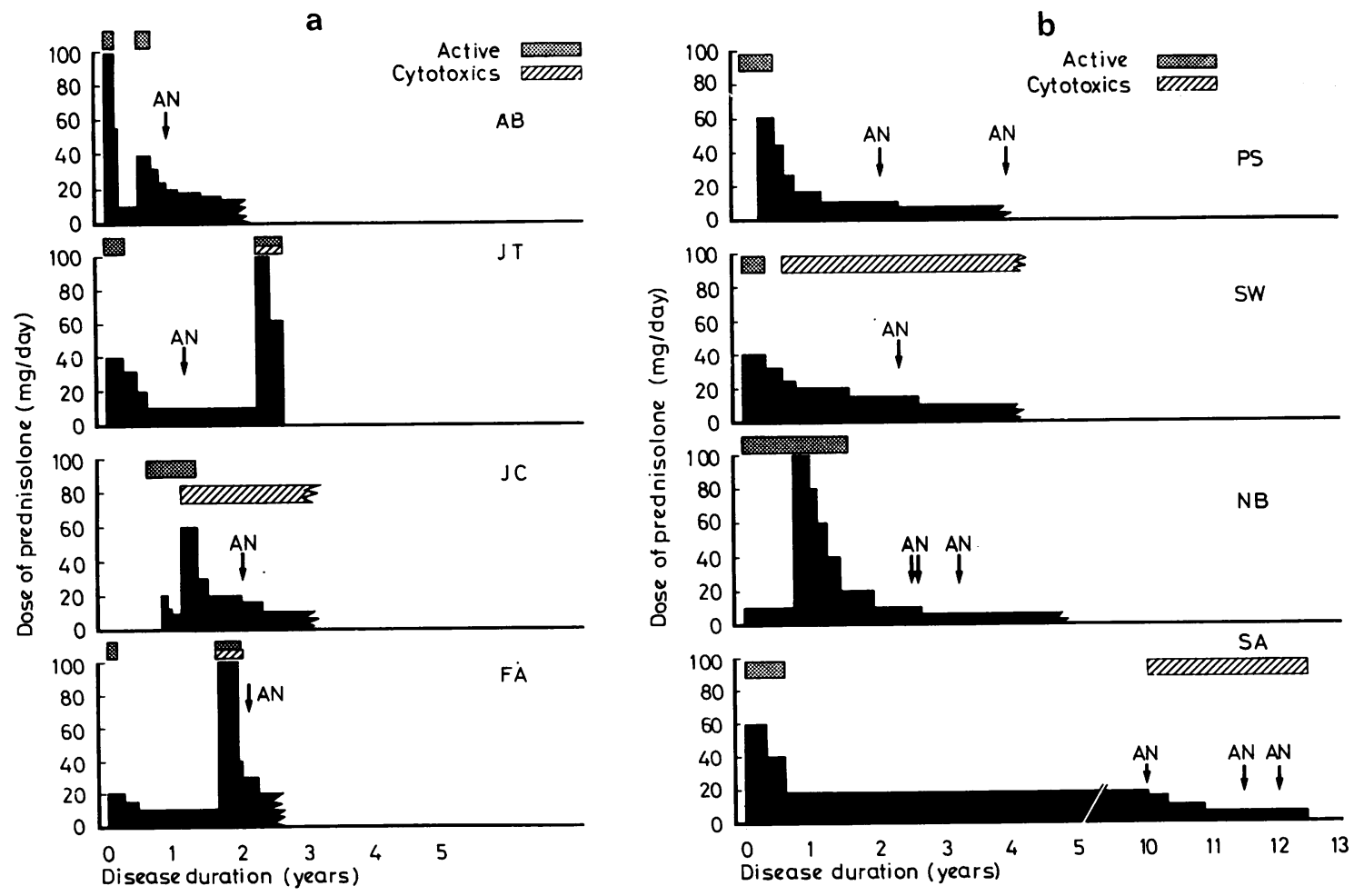

Fig. 11 a, b Chronological relationship of disease activity and therapy to onset of osteonecrosis AN symptoms 
correlation was observed between higher prednisolone dosage in the osteonecrosis group (Table 2). However, 3 patients went on to develop osteonesis of further joints in spite of the prednisolone dose being lowered below $10 \mathrm{mg} /$ day. No correlation was found between azathioprine or cyclophosphamide treatment and osteonecrosis.

Osteonecrosis tended to occur early in the disease, 7 patients developing it within 3 years of onset, and all patients had received relatively high doses of corticosteroids prior to the onset of symptoms (Fig. 11a, and b). However, the symptoms from osteonecrosis tended to occur when the disease had progressed from a cllnically active phase into a stage of clinical quiescence. The serological changes at the onset of osteonecrosis symptoms also suggested that the disease was inactive. The complement level was normal in all the patients in whom it was measured and the DNA binding values were normal in 2 patients and only moderately raised in another 5 patients (Table 3 ).

The duration from the onset of symptoms which were subsequently referable to osteonecrosis to radiological changes in the affected joint are listed in Table 4. Four patients with osteonecrosis of weightbearing joints had $x$-rays of the affected joints taken within 1 month of onset of symptoms, and although changes in the bone density were noted in some cases 5 to 7 months elapsed before radiological evidence

Table 2 Maintenance dose of prednisone prior to osteonecrosis

\begin{tabular}{lll}
\hline & $\begin{array}{l}\text { SLE patients } \\
\text { with osteonecrosis }\end{array}$ & $\begin{array}{l}\text { SLE patients } \\
\text { without } \\
\text { osteonecrosis }\end{array}$ \\
\hline Prednisolone $<10 \mathrm{mg} /$ day & 1 & $34 \dagger$ \\
Prednisolone $>10 \mathrm{mg} /$ day & 7 & 26 \\
\hline
\end{tabular}

$\mathbf{P}<0.05 . \dagger 12$ had never received corticosteroids. of collapse of the articular surface occurred. However, in non-weight-bearing joints, typical $x$-ray changes with involvement of the articular surfaces $\stackrel{\text { S }}{+}$ were present with the onset of symptoms.

\section{Discussion}

Osteonecrosis occurred in $12 \%$ of our SLE patients $\%$ and indirectly led to the death of 1 . In only 1 instance did an alternative explanation suggest itself, other than the underlying disease and its treatment, that $\vec{\omega}$ being the osteonecrosis of the left head of humerus in case 8, which occurred 14 months after a fracture of the surgical neck of the left humerus. The inci- $\omega_{\infty}$ dence of osteonecrosis in our series is not dissimilario from that recently reported by Smith et al. (1976). They observed symptomatic osteonecrosis in 7 out of 99 SLE patients; they also noticed a tendency for ? osteonecrosis to occur more commonly in the youngpatients and in those with leucopenia; neither of these associations were present in our population.

Table 4 Relationship of symptoms to radiological changes

\begin{tabular}{llll}
\hline Patient & Joint & $\begin{array}{l}\text { Symptoms to } \\
1 \text { st X-ray }\end{array}$ & $\begin{array}{l}\text { Symptoms to 1st } \\
\text { X-ray showing } \\
\text { involvement of } \\
\text { articular surface }\end{array}$ \\
\hline 1 & Hip & 1 month & 7 months \\
2 & Hip & 1 month & 1 month* (5 months) \\
3 & Hip & 9 months & 9 months \\
4 & Hip & 6 months & 6 months \\
5 & Hip & 1 month & 6 months \\
8 & Hip & 1 month & 6 months \\
7 & Knees & 12 months & 12 months \\
5 & Shoulder & 1 month & 1 month \\
8 & Shoulder & 1 month & 1 month \\
& Shoulder & 1 month & 1 month \\
6 & Wrist & 1 month & 1 month \\
\hline * Lytic area noted. & &
\end{tabular}

* Lytic area noted.

Table 3 Clinical and serological features of SLE patients with osteonecrosis

\begin{tabular}{|c|c|c|c|c|c|c|c|c|}
\hline \multirow[b]{2}{*}{ Case } & \multirow[b]{2}{*}{$\begin{array}{l}\text { Age at } \\
\text { onset SLE } \\
\text { (years) }\end{array}$} & \multirow[b]{2}{*}{$\operatorname{Sex}$} & \multirow[b]{2}{*}{$\begin{array}{l}\text { Duration } \\
\text { of } S L E \\
\text { prior to } \\
\text { osteonecrosis } \\
\text { (years) }\end{array}$} & \multirow[b]{2}{*}{$\begin{array}{l}\text { Joints involved } \\
\text { by osteonecrosis }\end{array}$} & \multirow[b]{2}{*}{$\begin{array}{l}\text { Max. Pred } \\
\text { dose (mg/day) }\end{array}$} & \multicolumn{3}{|c|}{ Onset of osteonecrosis symptoms } \\
\hline & & & & & & Clinical status & $\begin{array}{l}\text { DNA } \\
\text { antibody } \\
\text { level* } \\
\text { units } / m l)\end{array}$ & $\begin{array}{l}\text { Total } \\
\text { haemolytic } \\
\text { complement } \\
\text { levelt }\left(\mathrm{CH}_{50}\right.\end{array}$ \\
\hline 1 & 52 & $\mathbf{F}$ & 1 & Hip & 100 & Quiescent & 36 & 64 \\
\hline 2 & 30 & $\mathbf{F}$ & $1 \frac{1}{2}$ & Hip & 40 & Quiescent & - & - \\
\hline 3 & 19 & $\mathbf{F}$ & 2 & Hip & 60 & Quiescent & 66 & 62 \\
\hline 4 & 28 & $\mathbf{F}$ & 2 & Hip & 100 & Quiescent & 49 & 44 \\
\hline 5 & 25 & $\mathbf{F}$ & 2 & Hip and shoulder & 60 & Quiescent & 18 & 51 \\
\hline 6 & 16 & $\mathbf{F}$ & $2 \frac{1}{2}$ & Lunate & 40 & Quiescent & 31 & 40 \\
\hline 7 & 14 & $\mathbf{F}$ & $2 \frac{1}{2}$ & $\begin{array}{l}\text { Both knees and } \\
\text { elbow }\end{array}$ & 100 & Quiescent & 16 & 68 \\
\hline 8 & 46 & $\mathbf{F}$ & 10 & $\begin{array}{l}\text { Both shoulders } \\
\text { hip and }\end{array}$ & 60 & Quiescent & 30 & 57 \\
\hline
\end{tabular}

* DNA Ab-normal range $=<25$ units $/ \mathrm{ml}$. $+\mathrm{CH}_{50}-$ normal range $=36-72$ units $/ \mathrm{ml}$. 
Bergstein et al. (1974) found a $40 \%$ incidence of radiological osteonecrosis in 35 children with SLE. In their 14 patients with radiological osteonecrosis a total of 31 sites were involved, but only 9 of these were symptomatic. All their patients appeared to have received prednisolone $2 \mathrm{mg} / \mathrm{kg}$ body weight. A high incidence of osteonecrosis among children with SLE was also reported by Hurley et al. (1974), who described symptomatic AN in 4 out of 10 patients.

Controversy concerning the role of corticosteroids in the aetiology of osteonecrosis in SLE exists. In the original description of Dubois and Cozens (1960) 5 of their 11 cases were not receiving corticosteroids at the time of the onset of osteonecrosis, and 1 of these had never received steroids. Osteonecrosis in 2 patients with discoid lupus erythematosus who were not receiving corticosteroids have also been recorded (Siemsen et al., 1962; Leventhal and Dorfmann, 1974). However, most SLE patients with osteonecrosis are receiving corticosteroids (Leventhal and Dorfmann, 1974; Smith et al., 1976; Dubois, 1976) and all out patients were receiving steroids. The daily steroid dose in our series tended to be higher in the SLE patients with osteonecrosis than in those without. However, osteonecrosis progressed to involve further joints in 3 patients despite the steroid dosage being reduced.

Murray (1973) reviewed ostenecrosis following organ transplantation and found that the incidence fell from $34 \%$ to $10 \%$ when the mean dose of prednisolone given during the first 3 postoperative weeks was lowered from $2.9 \mathrm{~g}$ to $1.2 \mathrm{~g}$. Osteonecrosis following high-dose corticosteroid therapy has also been reported in several conditions where primary abnormalities of bone are not suspectedpemphigus, erythema multiforme, multiple sclerosis, and thrombocytopenic purpura (Heinmann and Freiberger, 1960), and also in a patient with an adrenal adenoma (Madell and Freeman, 1964).

The relationship between underlying disease and corticosteroid therapy in pathogenesis of osteonecrosis in SLE is made difficult because high doses of steroids tend to be reserved for patients with most active systemic disease. We, like Smith et al. (1976), were impressed by the tendency of osteonecrosis symptoms to occur when the disease had entered a clinically and serologically quiescent phase, usually after periods of active disease which had required high doses of steroids. It is possible that increased use of the joints during the remission may precipitate collapse of previously weakened bone.

The microscopic appearance of affected bone removed from SLE patients has not clearly shown the pathological process responsible for osteonecrosis. Leventhal and Dorfmann (1974) were unable to detect any histological evidence of vas- culitis in the surgically removed osteonecrotic femoral head specimens from patients with SLE. However, the specimens were inevitably obtained some considerable time after the onset of clinical and radiological changes. In our series we failed to detect any serological abnormality usually associated with systemic vasculitis at the onset of symptoms, but this does not exclude the possibility that vasculitis predisposes to bone ischaemia, which subsequently fails to heal because of continued use of corticosteroids. Occlusive lesions of subchondral capillaries have been found in certain situations, such as rabbits treated with high doses of corticosteroids, where there is an increase in capillary fat globules (Jaffe et al., 1972; Fisher, 1978) and in sickle-cell disease (Tanaka et al., 1956) where it has been postulated that the increased blood viscosity associated with the higher haemoglobin levels may explain the increased incidence of osteonecrosis in the SC rather than SS haemoglobinopathies (Keeling et al., 1974). Attempts to show a reduction in blood flow to bones affected by osteonecrosis by means of ${ }^{99} \mathrm{Tc}$ diphosphonate scintigraphy have been unsuccessful (D'Ambrosia et al., 1976), but prospective studies in high risk patients may reveal vascular changes prior to the onset of symptoms. At present the lack of confirmatory evidence that vascular occlusion is the cause of bone death in SLE caused us to prefer the term osteonecrosis to avascular necrosis.

Pain in weight-bearing joints frequently precedes radiological changes of osteonecrosis (Dubois, 1976), and in our series 5 to 7 months elapsed in some cases before radiological changes in the articular surfaces became apparent. A similar observation has also been made in patients with avascular necrosis associated with sickle-cell disease (Chung and Ralston, 1969). Sequential $x$-rays are required, therefore, if the diagnosis is not to be overlooked.

Weight-bearing joints are most commonly affected by osteonecrosis in SLE patients. In our series 7 of the 8 patients had disease of weight-bearing joints, and of the total of 13 joints involved 8 were weightbearing. This picture is again similar to that seen in in sickle-cell disease (Tanaka et al., 1956) but strikingly dissimilar from the pattern of joint involvement seen in divers, in whom the humeral heads are more commonly affected than the femoral heads (Ohta and Matsunage, 1974).

In 2 of our patients synovitis was observed at the site of subsequent osteonecrosis before the development of radiological changes. While the relevance of this is unknown, it can provide a diagnostic pitfall in that symptoms may be attributed purely to synovitis and an associated osteonecrosis over- 
looked. The tendency for multiple joints to be involved may complicate management (Ruderman and McCart, 1964). Three of our patients had multiple joint involvement, and reducing the dose of corticosteroids seemed to be ineffective in halting the progression.

In our experience osteonecrosis tended to occur early in the disease and usually followed periods of active disease and aggressive corticosteroid therapy. We consider that the presence of persisting pain, particularly in a weight-bearing joint, in patients with SLE whose disease is otherwise quiescent, suggests that osteonecrosis is the most likely cause.

\section{References}

Bergstein, J. M., Wiens, C., Fish, A. J., Vemier, R. L., and Michael, A. (1974). Avascular necrosis of bone in S.L.E. Journal of Pediatrics, 85, 31-35.

Chung, S. M. K., and Ralston, E. L. (1969). Necrosis of the femoral head associated with sickle-cell anaemia and its genetic variants. Journal of Bone and Joint Surgery, 51A, 33-58.

Cohen, A. S., Reynolds, W. E., Franklin, E. C., Kulka, J. P., Ropes, M. E., Shulman, L. E., and Wallace, S. L. (1971). Preliminary criteria for the classification of systemic lupus erythematosus. Bulletin on Rheumatic Diseases, 21, 643-648.

D'Ambrosia, R. D., Riggins, R. S., Stadalnik, R. C., and De Nardo, G. L. (1976). ${ }^{90}$ Tc Diphosphonate scintigraphy validated with tetracycline labelling. Clinical Orthopaedics, 121, 143-148.

Dubois, E. L., and Cozens, L. (1960). Avascular bone necrosis associated with S.L.E. Journal of the American Medical Association, 174, 996-971.

Dubois, E. L. (1976). Lupus Erythematosus, second revised edition, p. 341. University of Southern California Press: Los Angeles.

Fisher, D. E. (1978). The role of fat embolism in the aetiology of corticosteroid-induced avascular necrosis. Clinical Orthopaedics and Related Research, 130, 68-80.
Heinmann, W. G., and Freiberger, R. H. (1960). A.N. 秄 femoral and humeral heads after high dose corticosteroid therapy. New England Journal of Medicine, 263, 672-675.

Hurley, R. M., Steinberg, R. H., Patriquin, H., an Drummond ,K. N. (1974). A.N. of the femoral head isp childhood S.L.E. Canadian Medical Association Journa 111, 781-784.

Jaffe, W. L., Epstein, M., Heyman, N., and Mankin, H. 期 (1972). The effect of cortisone on femoral and humerat heads in rabbits. Clinical Orthopaedics, 82, 221-228.

Jones, J. P. (1978). Editorial Comment. Clinical Orthopaedics and Related Research, 130, 2-4.

Keeling, M. M., Lockwood, W. M., and Harris, E. A. (1974 A.N. and erythrocytosis in sickle-cell trait. New Englan, Journal of Medicine, 290, 424-444.

Leventhal, G. H., and Dorfmann, H. D. (1974). Asepti民 necrosis of bone in S.L.E. Seminars in Arthritis and Rheumatism, 4, 73-93.

McCullum, R. I., and Walder, D. N. (1966). Bone lesions ifis compressed air workers. Journal of Bone and Joint Surgerp? 48B, 207-235.

Madell, S. H., and Freeman, L. M. (1964). A.N. of bone i $\overrightarrow{\text { }}$ Cushing's syndrome. Radiology, 83, 1068-1070.

Murray, W. R. (1973). Hip problems associated with orga市 transplants. Clinical Orthopaedics and Related Research 90, 57-69.

Ohta, Y., and Matsunage, H. (1974). Bone lesions in divers Journal of Bone and Joint Surgery, 56B, 3-16.

Ruderman, M., and McCarty, D. J. (1964). Aseptic necrosis in systemic lupus erythematosus. A report of a case involving six joints. Arthritis and Rheumatism, 7, 709-717

Siemson, J. K., Brook, J., and Meister, L. (1962). Lupus erythematosus and A.N. A clinical study of 3 cases and review of the literature. Arthritis and Rheumatism, 492-501.

Smith, F. E., Sweet, D. E., Brunner, C. M., and Davis, J. S (1976). Avascular necrosis in S.L.E., and apparent pre3 dilection for young patients. Annals of the Rheumatio Diseases, 35, 227-232.

Tanaka. K, R., Clifford, G. O., and Axelrod, A. R. (1956) Sickle-cell anaemia (homozygous $\mathbf{S}$ ) with aseptic necrosił of femoral head. Blood, 11, 998-1008. 